RECEIVED

JAN 261998

OSTI

GA-A22735

CONF971065 -

\title{
COMPARISON OF CALCULATED NEUTRAL BEAM SHINE THROUGH WITH MEASURED SHINE-THROUGH IN DIII-D
}

by

H.K. CHIU and R. HONG

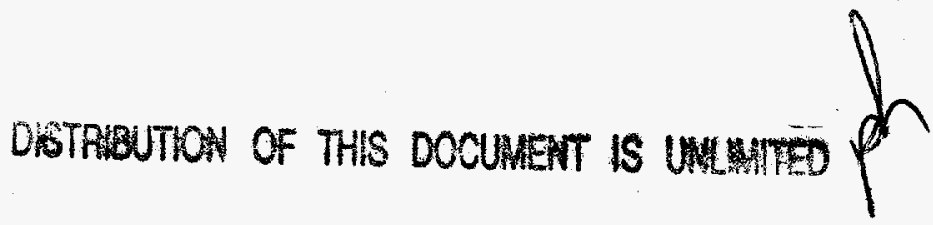

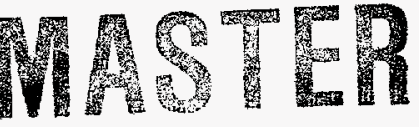

NOVEMBER 1997 


\section{DISCLAIMER}

This report was prepared as an account of work sponsored by an agency of the United States Government. Neither the United States Government nor any agency thereof, nor any of their employees, make any warranty, express or implied, or assumes any legal liability or responsibility for the accuracy, completeness, or usefulness of any information, apparatus, product, or process disclosed, or represents that its use would not infringe privately owned rights. Reference herein to any specific commercial product, process, or service by trade name, trademark, manufacturer, or otherwise does not necessarily constitute or imply its endorsement, recommendation, or favoring by the United States Government or any agency thereof. The views and opinions of authors expressed herein do not necessarily state or reflect those of the United States Government or any agency thereof. 


\section{DISCLAIMER}

Portions of this document may be illegible electronic image products. Images are produced from the best available original document. 


\title{
COMPARISON OF CALCULATED NEUTRAL BEAM SHINE THROUGH WITH MEASURED SHINE-THROUGH IN DIII-D
}

\author{
by \\ H.K. CHIU and R. HONG
}

This is a preprint of a paper to be presented at the 17th IEEE/NPSS

Symposium on Fusion Engineering, October 6-11, 1997, San Diego, California and to be published in the Proceedings.

\author{
Work supported by \\ the U.S. Department of Energy \\ under Contract No. DE-AC03-89ER51114
}




\title{
Comparison of Calculated Neutral Beam Shine Through with Measured Shine-Through in DIII-D*
}

\author{
H.K. Chiu and R. Hong \\ General Atomics \\ P.O. Box 85608 , San Diego, California 92186-9784
}

\begin{abstract}
A comparison of the calculated shine through of neutral particle beams in the DIII-D plasma to measured values inferred from the target temperature rise is reported. This provides an opportunity to verify the shine through calculations and makes them more reliable in those cases where the shine through can not be measured. The DIII-D centerpost neutral beam target tiles are safe-guarded against excessive beam shine-through by pyrometry and thermocouple (TC) arrays on the tiles. Shine-through beam power is calculated from the measured temperature changes reported by the target tile TC array. These measurements are performed at the beginning of each operational year at DIII-D. Theoretically, the beam energy deposited into the plasma can be expressed as a function of the change in beam density: $\mathbf{E}_{\mathbf{b} \rightarrow \mathbf{p}}=\varepsilon\left[\int(\mathbf{d t}) * \int(\mathbf{d V}) * \int\left(-\mathbf{d s N}_{\mathbf{b}}(\mathbf{s})\right)\right]$. The expression for beam density propagating in a plasma is: $\mathbf{d N}_{\mathbf{b}}(\mathrm{s}) / \mathbf{d s}=-\mathbf{N}_{\mathbf{b}}(\mathrm{s}) \mathbf{n}(\mathrm{s}) \sigma$. Where $\mathbf{N}_{\mathbf{b}}(\mathbf{s})$ is the beam particle density, $n(s)$ is the plasma density, $\sigma$ is the interaction cross section, and $\varepsilon$ is the energy per beam particle. The beam energy deposited onto the centerpost (shine-through) is then of the general form: $\mathbf{E}_{\mathbf{c p}}=\varepsilon$ $\left[\int(\mathbf{d t}) * \int\left(\mathbf{d V N}_{\mathbf{b}}(\mathbf{a})\right)\right]$,
\end{abstract}

where;

$$
\mathbf{N}_{\mathbf{b}}(\mathbf{a})=\mathbf{A}\left[\mathbf{N}_{\mathbf{b}}(\mathbf{0}) \mathrm{e}^{-(\mathrm{na} \sigma) \gamma}+\mathbf{C}\right]
$$

Given that a, is the plasma diameter, (na) is the line density. $\mathbf{N}_{b}(\mathbf{0})$ is the initial beam density, where $A, C$ and $g$ are system dependent constants. The line density and uncollided beam density are measured quantities. Values of $\sigma$ are available in the general literature. Neutral beam energy deposition in plasma (of known density) is inferred by comparing the results of a series of shine-through measurements for the 1997 campaign at DII-D to the expected shine-through given by theory.

\section{INTRODUCTION}

The fraction of beam energy deposited on the centerpost of a tokamak varies with the plasma density, and is indicative of the beam energy deposited in the plasma. Intuitively, one would expect a dense plasma would attenuate a beam of neutral particles more than a less dense plasma. Looking at the general expression for beam density at the centerpost, and writing $L$ and $L^{\prime}$ for differing plasma line densities; We have: $\mathrm{N}_{\mathrm{b}}(\mathrm{a}) \mathrm{l}_{\mathrm{L}}=A\left[\mathrm{~N}_{\mathrm{b}}(0) \mathrm{e}^{-(\mathrm{L} \sigma)^{\gamma}}+\mathrm{C}\right.$, $]$ and $\mathrm{N}_{\mathrm{b}}(\mathrm{a}) \mathrm{L}_{\mathrm{L}}=\mathrm{A}\left[\mathrm{N}_{\mathrm{b}}(0) \mathrm{e}^{-\left(\mathrm{L}^{\prime} \mathrm{a} \sigma\right) \gamma}+\mathrm{C}\right]$. The shine-through power is just: $N_{b}(a) l_{L} / N_{b}(0)=A\left[N_{b}(0) e^{-(n a \sigma)^{\gamma}}+C\right] / N_{b}(0)$, and $\left.N_{b}(a)\right\}_{L} / N_{b}(0)=A\left[N_{b}(0) e^{-\left(L^{\prime} \sigma \gamma \gamma\right.}+C\right] / N_{b}(0)$. The ratio of beam particles reaching the centerpost or the shine-through power as a function of plasma line density alone is:

$$
\left.\left.\mathrm{N}_{b}(a)\right|_{L} / N_{b}(a) \mid L^{\prime}=e^{-(} L^{\prime}-L^{)}\right) \gamma
$$

given that $\mathrm{C} \ll \mathrm{N}_{\mathrm{b}}(0)$. If the beam and target tile conditions are held constant, the logarithim of (2) should be linear with respect to changes in plasma line density:

$$
\operatorname{Ln}\left[\left.\mathrm{Nb}_{b}(\mathrm{a})\right|_{\mathrm{L}} /\left.\mathrm{N}_{\mathrm{b}}(\mathrm{a})\right|_{L^{\prime}}\right]=\left(\mathrm{L}-\mathrm{L}^{\prime}\right)(\sigma \gamma) \text {. }
$$

The system and transport dependent term $(\sigma \gamma)$ is then indicative of the density dependence of beam energy deposition in a plasma, for the given system constraints.

The neutral beam shine-through power was experimentally quantified by measuring the temperature rise on a set of well characterized centerpost graphite target tiles embedded with thermocouples, and illuminated by the beam [1]. The measured temperature rise in these tiles were correlated to input beam power by the relationship: $\mathrm{Ks}=\mathrm{Pd} \times \mathrm{t} / \Delta \mathrm{T}$ [1] The data presented here were measured during DIII-D shots 84384 to 84399 .

The calculated values for shine-through power were generated by the ONETWO plasma transport modeling code [2]. The beam plasma interaction module of the ONETWO code encapsulates the methodology of the FREYA [3], and NFREYA [4] models. In these models the energy deposition by the beam is expressed as: $\mathrm{Q}_{\mathrm{b}, \mathrm{e}}=$ $\Sigma_{c} f_{b, e, c} Q_{b, c}$ for electrons, and $\Sigma_{i} Q_{b, i}=\Sigma_{c} \Sigma_{i} f_{b, i, c} Q_{b, c}$ for the ions. The shine-through power in this case is the difference between the specified input beam power and the calculated beam power lost to the plasma.

Utilizing the logarithmic relationship derived for the density dependent shine-through power ratio (3), a comparision was made of the experimental results and the calculated results. Plotting out this linear functions for the

\footnotetext{
*Work supported by U.S. Department of Energy under Contract No. DE-AC03-89ER51114.
} 
measured and calculated shine-through, the system and transport dependent term $(\sigma \gamma)$ are compared. The experimental error in the shine-through power measurements is quantified as $\pm 5 \%$. The acceptance range for the calculated results is $\pm 7 \%$.

\section{MEASURED AND CALCULATED SHINE-THROUGH POWER RESULTS}

DIII-D shots 84384 to 84399 had values of $B_{T} \sim 1.8 \mathrm{~T}, \mathrm{~T}_{\mathrm{e}}$ $\sim 4 \mathrm{keV}$ and $\mathrm{T}_{\mathrm{i}} \sim 2.5 \mathrm{keV}$. The measured shine-through power as a function of line density is given in Fig. 1. The shine-through power for each line density normalized to the shine-through power of the lowest line density, is given in Fig. 2. Fig. 3 is a plot of (3) obtained for the measured shine-through power values.

Using values of $B_{T}=1.8 T, T_{e} \sim 4 \mathrm{keV}$ and $T_{i} \sim 2.5 \mathrm{keV}$, and the range of plasma line densities, a series of ONETWO calculations for beam power deposition were performed to simulate DIII-D shots 84384 to 84399 . The calculated shine-through power as a function of line density is given in Fig. 4. The shine-through power for each line density normalized to the shine-through power of the lowest line density, is given in Fig. 5. Fig. 6 is a plot of (3) obtained for the calculated shine-through values.

A plotted comparision of (3) obtained for the measured values, and the calculated values is presented in Fig. 7.

\section{CONCLUSIONS}

The calculated beam shine-through power is in reasonable agreement with the measured values. The calculations used the average $T_{e}$ and $T_{i}$, and assumed a static plasma density profile. The variations in local plasma density and

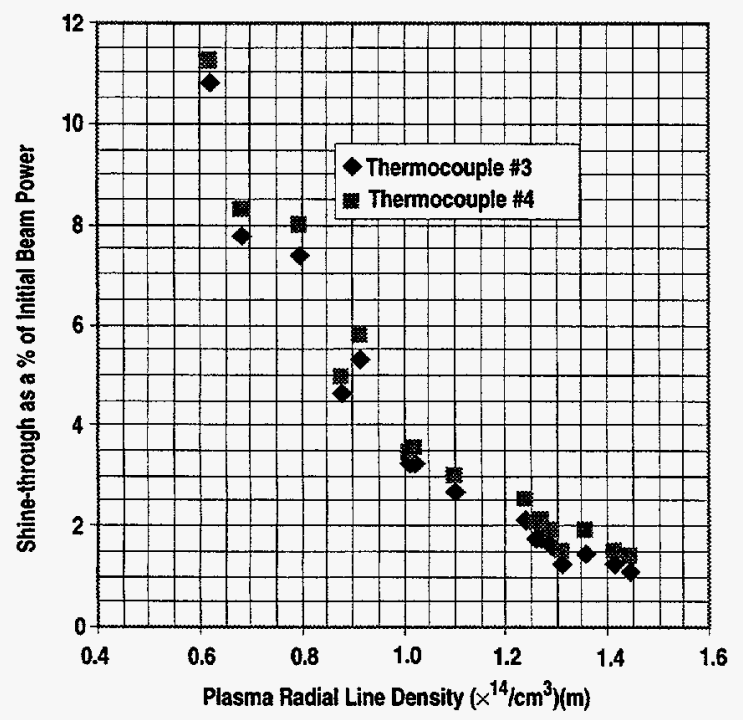

Fig. 1. Beam shine-through power as a function of line density.

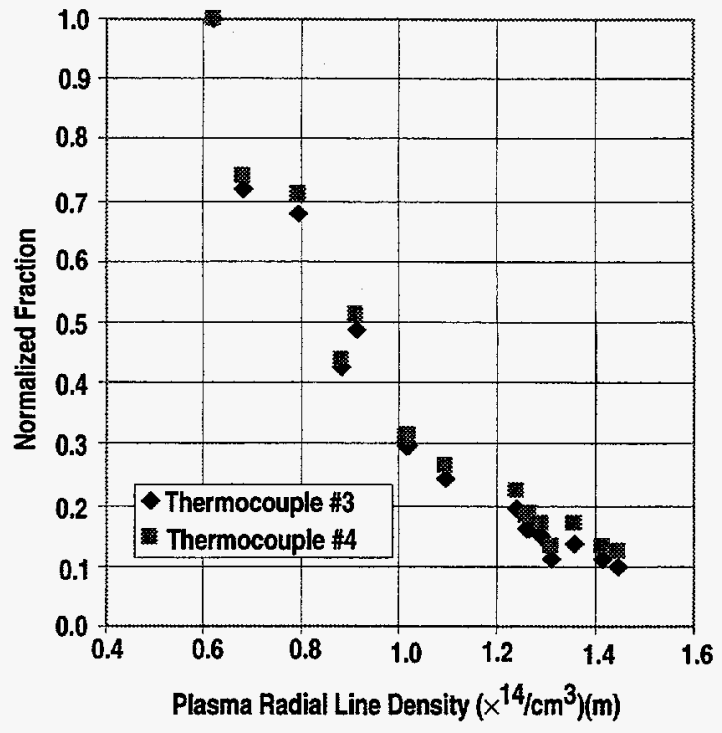

Fig. 2. Normalized shine-through power.

temperature would be sufficient to acount for the divergence in the calculated and measured values. The shine-through power fraction is predictable for a given plasma shape, temperature, and plasma confinement parameters via (3). Once the system and transport term is derived, the shine-through power for a range of plasma line densities can be extrapolated.

The beam energy deposited in the plasma is just the difference between the input power and the shine-through power. Hence, the beam power deposition in a given plasma shape and confinement parameters, can be extrapolated once a few values for shine-through power are either measured or calculated for those conditions.

This may expedite future calculations for beam power deposition.

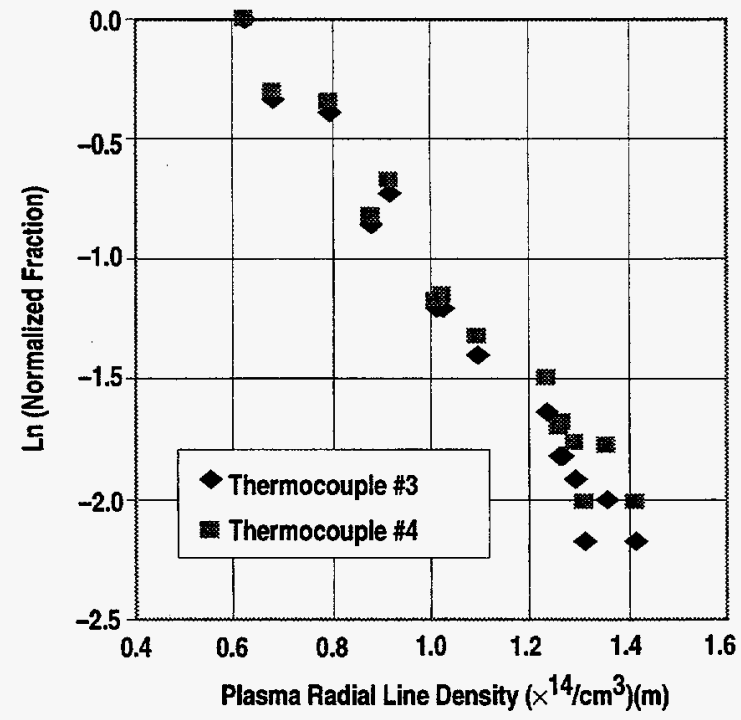

Fig. 3. Natural log of the normalized shine-through power fraction. 


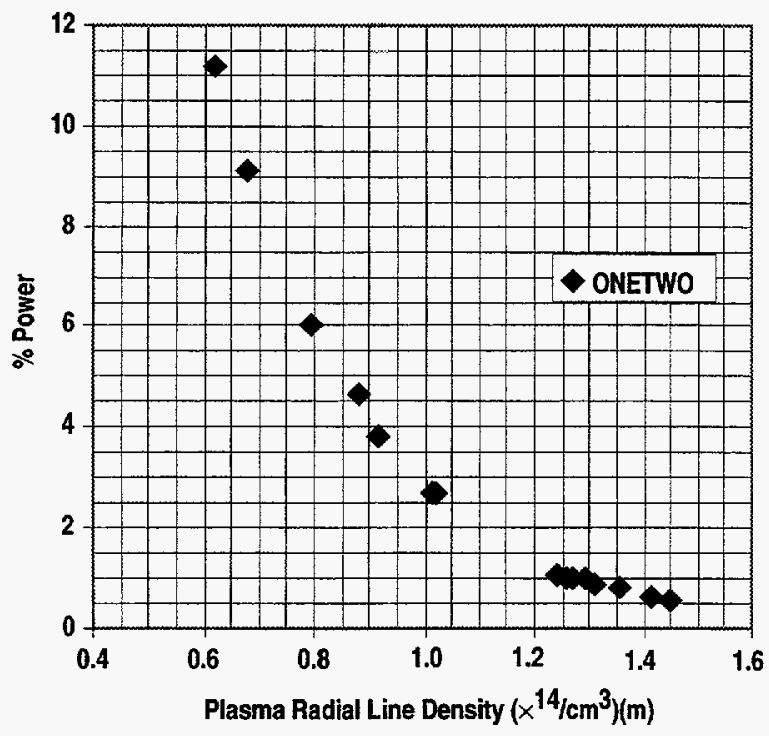

Fig. 4. The calculated shine-through power as a function of line density.

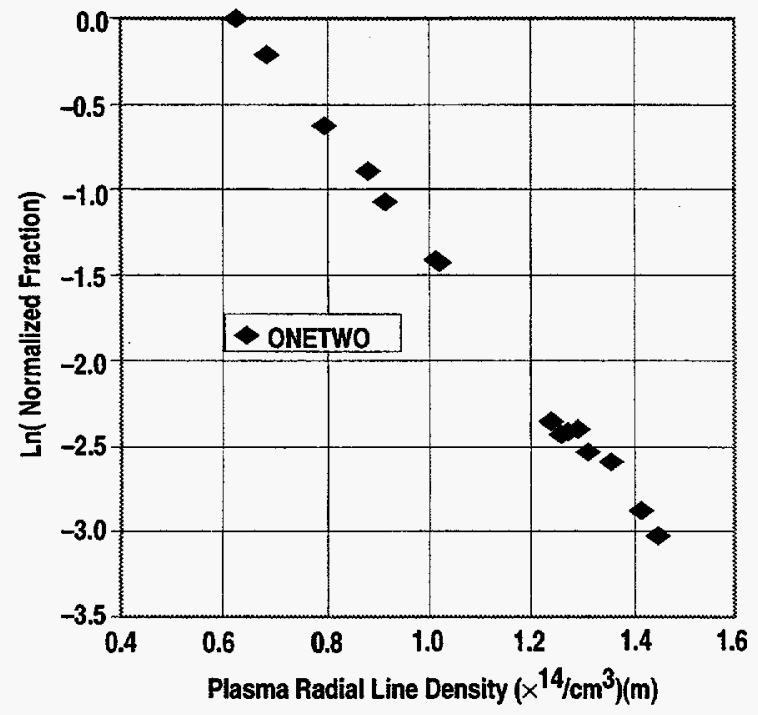

Fig. 6. Natural log of the normalized shine-through power fraction.

\section{ACKNOWLEDGEMENTS}

The authors would like to thank Matt Madruga and Bonnie Scoville for their assistance in operating the neutral beam systems and data acquistion for this study, and all the members of the DIII-D neutral beam operations group. Thanks to J.T. Scoville for his assistance in retrieving electron and ion temperatures for these plasma shots. Deepest appreciations to $\mathrm{H}$. St John for his patience and assistance with ONETWO.

\section{REFERENCES}

[1] S. Riggs, R. Hong, and D. Kessler, "Neutral beam shinethrough power and it's dependence on the line density of

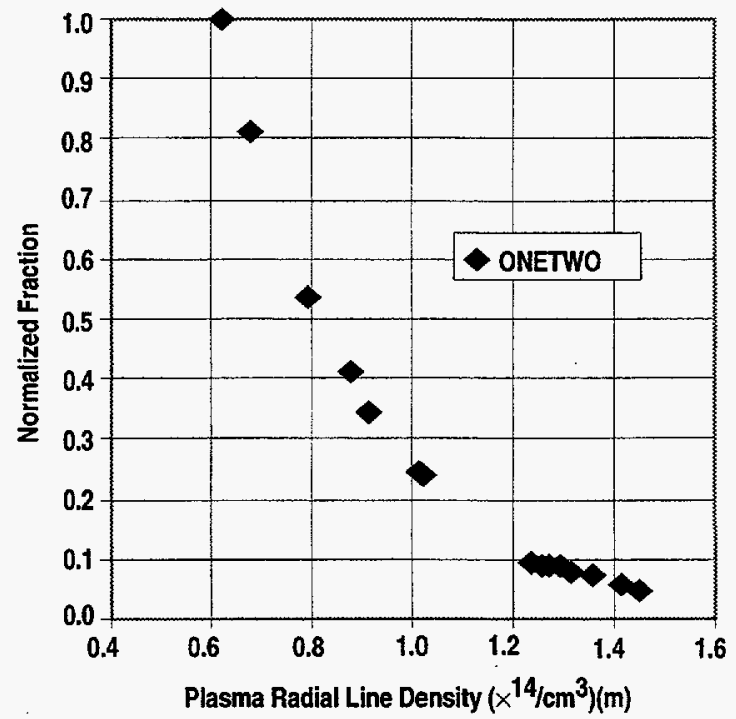

Fig. 5. Normalized shine-through power as a function of line density.

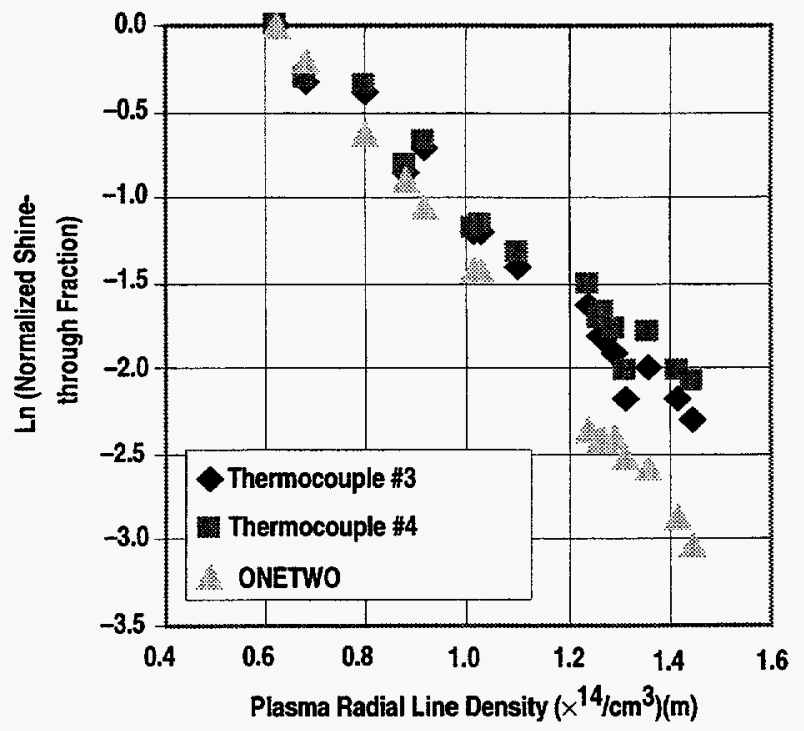

Fig. 7. Comparison between calculated and measured shine-through power fractions as a function of plasma line density.

the DIII-D plasma," Proc. of the 16th IEEE/NPSS Symposium on Fusion Engineering, Vol. 2, 856, Urbana, (1995).

[2] G.G. Lister, D.E. Post, and R. Goldston, Proc. of the 3rd Symposium on Plasma Heating in Torodial Devices, Varenna, 303 (1976).

[3] R.H. Fowler, J.A. Holmes, and J. Rome, "NFREYA--A Monte Carlo beam deposition code for noncircular tokamak plasmas," ORNL/TM-6845, Oak Ridge National Laboratory (1969).

[4] J.D. Callen, et al., Proc. of the 5th International Conference on Plasma Physics and Controlled Nuclear Fusion Research, Vol. 1, 645 (1974). 